\title{
Fei-Wen Cheng*
}

National Chiayi University, Taiwan

chengfw@mail.ncyu.edu.tw

\section{NEGOTIATING THEORETICAL IMPLICATION IN MANAGEMENT RESEARCH ARTICLE DISCUSSIONS}

\section{Abstract}

Demonstrating the theoretical contribution of new research is essential if the work is considered worthy of publication. This study draws upon genre-based research to explore the means by which theoretical implications are textually realized, negotiated, and promoted to readers in terms of their constituent components and argumentation patterns. By conducting a rhetorical analysis on the discussion section of 60 management research articles, the present study reveals theoretical implications are achieved through a combination of three constituent steps: Stating theoretical implication, Showcasing the theoretical background, and Justifying the theoretical value, and their related substeps. Three salient argumentation patterns are typically employed by research article (RA) authors to negotiate the theoretical value of the novel research. The findings indicate that to transform a new finding into disciplinary knowledge requires contextualizing that finding in a relevant theoretical domain, ascribing value to the finding and interpreting and explaining its meaning in terms of its theoretical insights. It also highlights pedagogical focus should illuminate the pathways for effectively defending and justifying the demonstrated theoretical value.

\section{Key words}

theoretical implication, discussion section, academic evaluation, genre research.

\footnotetext{
* Corresponding address: Fei-Wen Cheng, 85 Wenlong Village, Minxiong Township, Chiayi County, Taiwan 62117.
} 


\section{INTRODUCTION}

The research article (RA) has increasingly been portrayed as kind of hybrid promotional genre (Berkenkotter \& Huckin, 1995; Bhatia, 2004; Hyland, 2015), with different RA sections having their own distinctive communicative schemes to achieve promotional purposes. In the discussion section, this purpose is primarily achieved by assessing the value of the study's empirical findings in terms of their wider significance within the disciplinary context (Basturkmen, 2012; Geng \& Wharton, 2016; Lewin, Fine, \& Young, 2001; Swales, 1990). In prior ESP research on this section, the manifestation of the study's contribution has been identified via a rhetorical move or step, which indicates or states the value or significance of the research (e.g. Basturkmen, 2012; Nwogu, 1997; Yang \& Allison, 2003). This line of studies appears to construe research contribution in general terms, lumping theoretical, practical and methodological implications together into a single category without making meaningful distinctions among them. However, among these forms of contribution, advancement of theory stands out as the most articulated and prevalent form within the management discipline (Bartunek \& Rynes, 2010; Corley \& Gioia, 2011; Corley \& Schinoff, 2017).

The term "theoretical implication" refers to a discursive construction indicating a research article's contribution to the knowledge base of a specific disciplinary field (Bartunek \& Rynes, 2010; Colquitt \& Zapata-Phelan, 2007; Corley \& Gioia, 2011; Corley \& Schinoff, 2017; Cornelissen \& Durand, 2014). The importance of constructing theoretical implications in academic publications is more pronounced in the management discipline than in others (Corley \& Gioia, 2011; Cornelissen \& Durand, 2014; Shaw, Bansal, \& Gruber, 2017). This requirement has imposed a formidable burden on management scholars (e.g. Bergh, 2003; De Keyser, Guiette, \& Vandenbempt, 2019; Geletkanycz \& Tepper, 2012; Shaw et al., 2017). Yet, as Corley and Schinoff (2017: 7) observe, "regardless of the numerous articles and editorial commentaries defining and describing it [...] the practice of making a theoretical contribution continues to be shrouded in mystery." This is probably because most studies on the rhetorical practice of management RAs have centered on the construction of practical implications (Bartunek \& Rynes, 2010), the introduction (Lim, 2012; Locke \& Golden-Biddle, 1997) or the method section (Lim, 2006), with the exception of Lindeberg (2004) and Peacock (2002), who have focused on the discussion section. Yet, even these two studies did not address the discourse act of theoretical implication. Further research on its rhetorical construction in RA discussions is therefore warranted.

The current study was thus motivated by the lack of explicit pedagogical guidance available for construing theoretical implications, and the formidable challenges faced by novice scholars in attempting to negotiate the sophisticated rhetorical maneuvers underlying them (Corley \& Schinoff, 2017; Geletkanycz \& Tepper, 2012). It set out to probe the rhetorical practice of formulating theoretical implications through an examination of how theoretical implications are 
articulated and negotiated in management RA discussion sections. The goal of exploring this academic practice was to inform management scholars on ways to effectively orchestrate the theoretical innovations reported in the RA discussion section that enhance the field's knowledge.

\section{LITERATURE REVIEW}

\subsection{Conceptual framework for the study of theoretical implication}

Given the disciplinary emphasis on the explicit articulation of theoretical implications as criteria for publication, management science has generated a substantial amount of research and editorial commentary to explore this construct, such as the definition of theory in the fields of management and organization (e.g. Whetten, 1989), the taxonomy or criteria used to assess the quality of theoretical contributions (e.g. Colquitt \& Zapata-Phelan, 2007; Corley \& Gioia, 2011), or the thinking tools that facilitate theoretical innovation (e.g. "disciplined imagination", "problematization", and "thickening this abstraction", see a comprehensive review in Cornelissen \& Durand, 2014).

Of particular relevance to the present study is the empirical research aimed at clarifying what constitutes 'theoretical contribution'. As expounded by Corley and Gioia (2011), the dominant criterion for articulating and assessing theoretical implications is originality, which can exist in varying levels. Corley and Gioia (2011: 16), for example, observe that originality can be represented as "either an incremental or a more revelatory or surprising advance in understanding [...] of what reviewers and editors currently consider to be a theoretical contribution worthy of publication." They contend that the notion of theoretical implication can embrace differing levels of originality, from extending or refining the current state of scientific knowledge, to adding nuance or incremental improvements to our existing understanding (incremental originality), to offering a fundamentally new way of seeing a phenomenon (revelatory originality) (Corley \& Gioia, 2011). This perception is further consolidated in Geletkanycz and Tepper's (2012: 259) conceptualization of theoretical implication as provided when "a study changes, challenges or otherwise fundamentally advances existing theoretical understanding". Cornelissen and Durand (2014: 995) echo this view in their reference to theoretical implication as "scholarly insight that creates, refines, or extends management theory."

Underlying this view is an assumption that the current state of disciplinary knowledge, as established in the literature, serves as the basis for identifying and evaluating a theoretical implication. As Geletkanycz and Tepper's (2012: 257) have argued, "critical here is a bridge between a study's findings and the larger literature." Their perspective highlights that the way in which a new finding is 
positioned within the disciplinary knowledge landscape is key to constructing theoretical implication. This feature, along with the wide-ranging scope of theoretical implication mentioned above, is taken as a starting point for defining this elusive concept and providing a comprehensive account of its rhetorical construction in this study.

\subsection{Rhetorical construction of research value in discussion sections of RAs}

Although a substantial amount of literature in management studies has focused on the significance and definition of theoretical implications, there have been no attempts to elucidate the rhetorical construction of theoretical implication in the RA discussion section. However, ESP studies in general have included research contribution as a discourse act in RA discussions (e.g. Yang \& Allison, 2003). This line of literature serves as the point of departure for the present study because theoretical implication is affiliated with the general contribution act. These studies have mainly drawn on the genre-based approach established by Swales (1990, 2004). In Swales's conceptualization, genre consists of underlying organizational or schematic structures and is realized by sequential moves occurring in a typical pattern. A move refers to "a discoursal unit or rhetorical unit that performs a coherent communicative function in written or spoken discourse" (Swales, 2004: 29). It can be enacted by either one step or a combination of steps.

These studies have indicated that a rhetorical act pertinent to the value or contribution of a novel study is encoded as the Step of 'Indicating the value or significance of the research' in the Move of 'Evaluating the study' (Liu \& Buckingham, 2018 on applied linguistics; Liu \& Lim, 2014 on economics; Tessuto, 2015 on law; Yang \& Allison, 2003 on applied linguistics), the Step of 'Indicating significance of the outcome' in the Move of 'Explaining specific research outcomes' (Nwogu, 1997 on medical science), the Step of 'Claiming value of results' in the Move of 'Consolidating results' (Kanoksilapatham, 2015 on three engineering subdisciplines), the 'Boost' Step (Lindeberg, 2004 on three disciplines including management), or the Move of 'Claim' (indicating either contribution to research or recommendation, Peacock, 2002 on seven disciplines including management).

As shown, prior ESP researchers have made commendable efforts to consolidate the pivotal role of the general contribution act in RA discussions, but we still lack a theoretically-grounded examination of theoretical implication. In other words, the question remains as to how claims of contribution to theory are textually constructed. Corley and Gioia (2011: 12) point out that this academic practice is considered critical in the management discipline because "every top-tier management journal requires a theoretical contribution before a manuscript will be considered for publication." Another question concerns how the value of new research and the importance of intellectual breakthroughs are negotiated in texts. 
As Bergh (2003: 136) contends, authors at this point should "do more than just mention the contribution - [they should] articulate and defend it". These are critical issues for practice and pedagogy, and the dearth of empirical investigation in ESP scholarship is surprising.

Thus, the present study seeks to address the following research questions by drawing upon genre-based research:

1. What constituent elements shape the rhetorical act of claiming theoretical implications in RA discussion sections?

2. Which argumentation patterns can be observed as authors argue and justify the value of a theoretical implication?

\section{METHOD}

\subsection{Corpus compilation}

A corpus of 60 RA discussion sections was compiled from four leading management journals, based upon impact factors provided by the ISI Web of Science (2013) and consultations with disciplinary experts. These journals were the Academy of Management Journal (AM), the Journal of Management (JOM), the Administrative Science Quarterly (ASQ), and the Journal of Management Studies $(J M S)$, with ISI impact factors of $6.230,6.051,5.316$, and 4.260 respectively. All are dedicated to publishing empirical and theoretical articles advancing management or organization knowledge apart from a distinct emphasis on subdomains.

Fifteen articles from each journal, published in 2011 or 2012, were selected based on the following criteria: First, the texts were required to report empirical studies based upon primary research. Theoretical papers, review studies and meta-analysis studies were thereby excluded. Second, they were required to follow a distinguishable Introduction-Method-Result-Discussion (IMRD) format, including a stand-alone discussion section. Articles that met these criteria were shortlisted and randomly selected to build the corpus. PDF files of the chosen articles were downloaded from the on-line journal websites. The discussion sections in the target pool were then converted into plain text format, so that figures, tables, footnotes/endnotes, reference lists, page numbers and running titles were removed. Table 1 summarizes the size of the corpus by journal. 


\begin{tabular}{|l|l|l|l|l|}
\hline JouRnALS & ARTICLES & $\begin{array}{l}\text { TOTAL WORD } \\
\text { COUNT OF ALL RAS }\end{array}$ & $\begin{array}{l}\text { TOTAL WORD COUNT } \\
\text { OF ALL DISCUSSION } \\
\text { SECTIONS }\end{array}$ & $\begin{array}{l}\text { MEANS (SD) OF } \\
\text { DISCUSSION } \\
\text { SECTIONS }\end{array}$ \\
\hline $\begin{array}{l}\text { Academy of } \\
\text { Management Journal }\end{array}$ & 15 & 196,510 & 41,939 & $2,796(400.9)$ \\
\hline $\begin{array}{l}\text { Administrative Science } \\
\text { Quarterly }\end{array}$ & 15 & 191,574 & 33,150 & $2,210(569.3)$ \\
\hline Journal of Management & 15 & 142,783 & 37,498 & $2,499.9(625.2)$ \\
\hline $\begin{array}{l}\text { Journal of Management } \\
\text { Studies }\end{array}$ & 15 & 147,853 & 31,077 & $2,071.8(466.6)$ \\
\hline Total & $\mathbf{6 0}$ & $\mathbf{6 7 8 , 7 2 0}$ & $\mathbf{1 4 3 , 6 6 4}$ & $\mathbf{2 , 3 9 4 . 4 ( 5 8 1 . 7 )}$ \\
\hline
\end{tabular}

Table 1. Corpus composition

\subsection{Analytical framework}

To identify the rhetorical practices with which theoretical implications were formulated, a preliminary analysis of the whole schematic structure of management RA discussions was undertaken. First, to capture more comprehensively the rhetorical functions found in management discussions, the aforementioned conceptual framework of theoretical implication derived from management scholarship and the rhetorical schemes of RA discussion sections noted in the ESP literature served as departure points. These were further integrated with a contextualist view of rhetorical structure proposed by Tseng (2018). It was advocated to address the difficulty in identifying the purpose of a rhetorical structure, as a discoursal unit can serve multiple purposes depending on its location in the RA section, subsection or move environment. For instance, within the discussion section, the act of reporting a result can serve different purposes depending on its location, such as justifying its practical/pedagogical implications or theoretical implications. To resolve this problem, this contextualist perspective underscores the importance of considering the context of moves and steps in identifying a rhetorical element in relation to the function/purpose of the element. That is, contextual information is necessary to decide what purposes a text segment accomplishes. Contextual information is broadly conceived of as subheadings, the entire RA section, subject matter of the article, knowledge of the discipline, and conventions of academic writing. More crucially, this perspective emphasizes that in the RA writing context, move structure should be considered in parallel with the discourse development of ideas, contributing to "coherence" and "the persuasion of argumentative writing" (Tseng, 2018: 83). In this way, any text segment associated with the same communicative and persuasive purpose will be labeled as the same move.

To develop an initial classification of move/step categories in pursuit of a comprehensive account of possible structures, the researcher went through a multi-iterative procedure of reading the RA sections preceding the discussion section to obtain an overall picture of the paper, then repeatedly analyzing the 
discussion section on the basis of text comprehension and semantic/functional features (cf. Basturkmen, 2009, 2012; Del Saz-Rubio, 2011; Martín \& León Pérez, 2014; Swales, 2004), until all the possible move/step elements were exhausted. Disciplinary informants (i.e. management scholars acting also as the inter-coders of the present analysis) were consulted on the comprehension and interpretation of the management articles in the pilot coding process.

Based on an initial coding of half of the target corpus, a final rhetorical scheme of management RA discussion sections was developed, composed of six moves with embedded steps (see Table 2), in which most rhetorical schemes had been identified in the previous literature with some newly added elements typically manifested in the target corpus. Note that the conclusion move is included in this scheme, as it usually forms part of the management discussion section, with or without a subheading label, at the end of the article. Also, only the embedded steps of Move 2 were specified given their relevance to the current discussion.

\begin{tabular}{|l|l|}
\hline Move & Constituent components \\
\hline Move 1: Giving an overview of the study & \\
\hline Move 2: Establishing theoretical implication & $\begin{array}{l}\text { Step 1: Stating theoretical implication } \\
\text { Step 2: Showcasing the theoretical background } \\
\text { Step 3: Justifying the theoretical value }\end{array}$ \\
\hline Move 3: Stating practical implications & \\
\hline Move 4: Evaluating methodology & \\
\hline Move 5: Indicating directions for future research \\
\hline Move 6: Stating conclusion
\end{tabular}

Table 2. Analytical framework of management RA discussions

\subsection{Reliability}

Prior to the data coding of the complete corpus, reliability analysis was conducted, for which three university faculty members were invited to act as inter-coders. Two of these were management academics, who had published widely in international top-tier journals. The third was an English faculty member of a foreign language department, who held an MBA degree and a PhD in education. The inter-coder procedure began with a training session for each coder on the rhetorical scheme of the discussion section, followed by a session of guided coding practice with the discussion section of one RA. After this, each inter-coder independently coded each move/step in five randomly selected discussion sections from the corpus. In total, 15 of the 60 discussions in the target corpus (25\%) were coded twice, once by the researcher and once by one of the three inter-coders. Cohen's kappa was used to calculate inter-coder agreement for the moves and steps embedded in the move of 'theoretical implication.' Across the six moves, the 
obtained kappa values ranged from .90 to .93 between the researcher and three inter-coders overall, and from .75 to .81 for the three steps in the theoretical implication move. These kappa statistics constitute a substantial to excellent agreement rate, according to Landis and Koch (1977). Cases with discrepancies between coders were resolved either by seeking the assistance of another coder, or by thorough discussions between coders, until agreement was reached.

\subsection{Data coding}

The remaining 45 discussion sections were then analyzed manually by the researcher, with the help of O'Donnell's (2012) UAM Corpus Tool (version 2.8), a free annotation application for discourse and linguistic analysis at multiple levels. First, to explore how theoretical implications were presented and justified within this disciplinary framework, the different constituent moves of the above model (see Table 2) were examined using a functional/semantic approach. As shown in Table 3, 235 occurrences of Move 2 'Establishing theoretical implications' were identified, with an average of 3.92 occurrences per article. The mean length of this move per article was 960.98 words $(S D=462.31$ ), accounting on average for 44.63 percent of each RA discussion (mean length $=2,394.4$ words, $S D=581.7$, as indicated in Table 1). The length and frequency of this section fully demonstrates its importance in the current corpus.

\begin{tabular}{|c|c|c|c|c|}
\hline \multirow[t]{2}{*}{ Journals } & \multirow[t]{2}{*}{ Articles } & \multirow{2}{*}{$\begin{array}{l}\text { Total number } \\
\text { of occurrences } \\
\text { of Move } 2\end{array}$} & \multicolumn{2}{|c|}{ Word counts of Move 2 per article } \\
\hline & & & Means & SD \\
\hline $\begin{array}{l}\text { Academy of Management } \\
\text { Journal }\end{array}$ & 15 & 71 & $1,227.47$ & $(599.25)$ \\
\hline $\begin{array}{l}\text { Administrative Science } \\
\text { Quarterly }\end{array}$ & 15 & 59 & 912.33 & $(423.07)$ \\
\hline Journal of Management & 15 & 54 & 799.20 & (379.73) \\
\hline Journal of Management Studies & 15 & 51 & 904.93 & $(331.55)$ \\
\hline Total & 60 & 235 & 960.98 & (462.31) \\
\hline
\end{tabular}

Table 3. Composition and length of Move 2

After specifying the different moves across the corpus, the three constituent steps of Move 2 and their embedded substeps (see Table 4 below) were identified, based primarily on prominent semantic/functional features, following the procedure set out above. The frequencies of occurrence of (sub)steps in Move 2 across the corpus were subsequently counted.

To account for the complexity and subtlety involved in negotiating the theoretical value, the argumentation patterns were identified and categorized within each Move 2. Here, the argumentation pattern refers to the prototypical ordering of rhetorical components to represent and negotiate the theoretical value 
of the RA. Given that Move 2 in the current scheme is the most complex, and that there are various strategies to perform this move, its organization patterns were categorized either by the fronting of Step 1 or by its presence or absence along with the fronting of other Steps, without taking account of its follow-up elements. Step 1 captures the cornerstone characteristics of this move, as this opening act is important in pinpointing what is given primacy in framing the constellations of arguments and may determine the argumentative orientation toward the desired rhetorical goal. This reliance on Step 1 for pattern classification is also rooted in the fact that it is a preferred opening step of this move as revealed in the current corpus. It should be borne in mind that no fixed pattern of strict sub-step sequence for each argumentation type can be identified, given that each of the three constituent steps along with its sub-steps may occur recursively and flexibly, but may not always occur in each move unit.

\section{RESULTS}

\subsection{Step components in establishing theoretical implication move}

As noted above, Move 2 claims research value with regard to the extension, refinement or challenging of the established literature in a discipline for the purpose of advancing a discipline's theoretical basis and thus strengthening its intellectual vitality.

\begin{tabular}{|c|c|c|c|c|}
\hline Step & $\begin{array}{l}\text { Raw } \\
\text { counts of } \\
\text { occurrence }\end{array}$ & $\begin{array}{l}\text { Means/per } \\
\text { move } \\
\mathrm{N}=235\end{array}$ & $\begin{array}{l}\text { Means/ } \\
\text { per article } \\
\mathrm{N}=60\end{array}$ & $\begin{array}{l}\text { Number of articles } \\
\text { containing the } \\
\text { (sub)step } \\
\mathrm{N}=60\end{array}$ \\
\hline Step 1: Stating theoretical implication & & & & $60 / 60(100 \%)$ \\
\hline Step 1A: Highlighting contribution to the field & 314 & 1.34 & 5.23 & $55 / 60(92 \%)$ \\
\hline Step 1B: Expressing consistency with past research & 111 & 0.47 & 1.85 & $46 / 60(77 \%)$ \\
\hline Step 1C: Expressing inconsistency with past research & 50 & 0.21 & 0.83 & $31 / 60(52 \%)$ \\
\hline $\begin{array}{l}\text { Step 1D: Expressing consistency/inconsistency with } \\
\text { hypothesis/ proposition }\end{array}$ & 25 & 0.11 & 0.42 & $17 / 60(28 \%)$ \\
\hline Step 2: Showcasing the theoretical background & & & & $58 / 60(97 \%)$ \\
\hline Step 2A: Reviewing the state of the field & 187 & 0.80 & 3.12 & $56 / 60(93 \%)$ \\
\hline Step 2B: Evaluating prior research & 112 & 0.48 & 1.87 & $49 / 60(82 \%)$ \\
\hline Step 3: Justifying the theoretical value & & & & $60 / 60(100 \%)$ \\
\hline Step 3A: Presenting results/research purpose & 314 & 1.34 & 5.23 & $58 / 60(97 \%)$ \\
\hline Step 3B: Interpreting results & 178 & 0.76 & 2.97 & $54 / 60(90 \%)$ \\
\hline Step 3C: Explaining results & 167 & 0.71 & 2.78 & $50 / 60(83 \%)$ \\
\hline Step 3D: Evaluating the results & 36 & 0.15 & 0.60 & $28 / 60(47 \%)$ \\
\hline
\end{tabular}

Table 4. Step components and distributions of Move 2 
In this study it was found that a template for the effective construction of Move 2 could be derived through a combination of three possible steps and several interrelated sub-steps, as shown in Table 4 above (see the Appendix for illustrative examples of each sub-step).

Step 1 'Stating theoretical implication' explicitly articulates the theoretical value by constructing a relationship between current findings and prior established knowledge, that is, the extent to which the new research expands our knowledge of the phenomenon under investigation. This step highlights the signposting function of spotlighting the status of the focal study along the knowledge construction continuum. Serving as a bridge between the new result and the larger theoretical literature, Step 1 is also a launch pad for the ensuing argumentation - a full-blown delineation of current understanding in the existing literature (Step 2) and forceful deliberations on the novelty of the findings (Step 3). Step 2 'Showcasing the theoretical background' tacitly sets the scene for the theoretical implication pertaining to the move, by framing and evaluating the current knowledge state related to the phenomenon under investigation. Step 3 'Justifying the theoretical value' is utilized to defend the theoretical implication demonstrated in Step 1, by describing and commenting on the new knowledge based upon current findings. It plays a critical role in theorizing an empirical finding into scientific knowledge and in this way justifies the claim of value in the theoretical implication.

Step 1 can be further divided into four sub-steps: (i) Step 1A refers to overtly promoting the theoretical contribution through linguistic expressions; (ii) Step 1B shows how the result adds one more piece of evidence to the extant literature, bolstering its support for a specific perspective or theory in the discipline's common stock of knowledge, and thus energizes a certain direction for target domain knowledge (Geletkanycz \& Tepper, 2012); (iii) Step 1C invokes an academic conflict between the present results and the established literature, which entails creating a knowledge space for the new research findings and construes opportunities for the contribution to be made (Geletkanycz \& Tepper, 2012); (iv) Step 1D indicates support for or refutation of the stated hypotheses or propositions in the literature review, which are primarily spawned from extant literature and can be conceptualized as variations of Steps $1 \mathrm{~B}$ and 1C. These substeps show plausible pathways for the articulation of theoretical implication, extending beyond the overt indexing of theoretical contribution to encompass a broader formulation by making comparisons and contrasts with established literature.

The relative frequencies of the substeps in Step 1 index the following features characterizing the management discipline: its emphasis on promotional features (Step 1A) and on establishing intricate connections between the study and prior literature (Steps 1B-1D). Step 1A is the leading strategy in this move unit, registering the highest frequency count $(\mathrm{N}=314,92 \%)$ in the current corpus $(\mathrm{N}$ indicates the raw counts of occurrences while the percentage shows the 
proportion of articles containing the substep. These numbers are not derivable from each other). However, as found in previous studies examining similar rhetorical components (e.g. indicating general significance of the research) in RA discussion sections, Step 1A remains a less common option in other disciplines; for example, $45 \%$ in economics (Liu \& Lim, 2014), 25\% to 42.86\% in three subdisciplines of engineering (Kanoksilapatham, 2015), and 57\% in law (Tessuto, 2015). The perceptibly higher frequency of this sub-step in this study reinforces Lindeberg's (2004) claim that clearly putting forward the research contribution has become established as the disciplinary norm in management studies. This can be ascribed to the increased level of competition that management scholars confront in seeking publication in the most selective journals.

On the other hand, the emphasis found in this work on highlighting theoretical implications by showing how they support or challenge prior formulations in established literature (Step 1B, 1C) is traditionally conflated into the step of comparing results with other studies. Although comparison across studies of the rhetorical step(s) proves difficult due to notable variations of rhetorical schemes, the act of comparing results with other studies was reported to be less prevalent in Kanoksilapatham (2015) and in Tessuto (2015), with frequency of occurrence ranging from $5.56 \%$ to $71.42 \%$ in three engineering subdisciplines, and 36\% in law. The paucity of 'Step 1D: Expressing (in)consistency with hypothesis/proposition' is also compatible with the findings of Liu and Lim (2014) in economics, with an incidence of $17.5 \%$. The low occurrence of this substep seemed to be due to the fact that its enactment was restricted to studies based on a hypothesis-testing research design.

Step 2 offers either a succinct or a comprehensive account of relevant literature, illustrating the theoretical background of this move, as a context of accepted knowledge needs to be established as the foundation for advancing a claim of theoretical innovation. This step can be further divided into reporting (Step 2A) or evaluating (Step 2B) the current state of disciplinary knowledge. Interestingly, Step 2A enjoys a higher frequency of occurrence $(\mathrm{N}=187,93 \%)$ than Step 2B $(\mathrm{N}=112,82 \%)$, indicating that to warrant a trajectory for demonstrating theoretical value, the researchers often opt to report the state of the field (Step 2A) and are less prone to overt evaluation or outright critique of prior literature (Step 2B).

Among the four components of Step 3, 'Step 3A: Presenting results' stands out as the most dominant, as the novel findings obtained are platforms from which theoretical innovation may be generated. The frequencies of 'Step 3B: Interpreting results' and 'Step 3C: Explaining results' are only slightly lower than those of Step 3A, Step 1A and Step 2A, indicating their critical role in this move. Step 3B involves generalizing the new finding to a higher level of abstraction while Step 3C provides justification of how and to what extent new findings are superior to, divergent from, or consistent with the existing literature, as flagged in Step 1. According to studies on the sociology of science, to construct a new knowledge claim, scientists 
need to move from their specific observed finding (lower-level epistemic claim) to generalized theoretical statements (higher-level epistemic claim) (Knorr-Cetina, 1995; Latour, 1987 as cited in Kelly \& Takao, 2002: 318-320). Both substeps serve to position findings in a broader theoretical discussion and thus constitute a higher level of epistemic claim in the course of theory development. Such empirical generalization is considered necessary in order to transform the new findings into knowledge that will be acknowledged by the academic community and to reinforce the strength of the claimed theoretical value.

\subsection{Argumentation patterns in negotiating theoretical implication}

Move 2, as shown in the current rhetorical scheme, is primarily instantiated in the sequential order of Steps 1-2-3, in which overt acknowledgement of theoretical implication precedes elaboration of current knowledge state and justification of theoretical value. In fact, the discursive construction of this move entails rather complex rhetorical maneuvers, often calculated to market the new research to readers. In this study, Move 2 is manifested in three distinct argumentation patterns. Pattern A always initiates with Step 1, regardless of the steps following it. Instead of fronting a categorical theoretical implication, Pattern B launches either with Step 2 or 3, showing that writers may spotlight established knowledge or feature novel findings at the outset. Pattern $\mathrm{C}$ also commences with Step 2 or 3 but is distinct from Pattern B in the absence of Step 1.

As displayed in Table 5, the current corpus contains 235 occurrences of Move 2. Among these, Pattern A (66\%) stands out clearly as the preferred argumentation option for this move, followed by Pattern B (31\%) and at a large distance by Pattern C (3\%).

\begin{tabular}{|c|c|c|c|c|}
\hline & Pattern A & Pattern B & Pattern C & Total \\
\hline Move frequency & $155 / 235(66 \%)$ & $72 / 235(31 \%)$ & $8 / 235(3 \%)$ & $\mathrm{N}=235$ \\
\hline $\begin{array}{l}\text { Number of articles } \\
\text { containing each pattern }\end{array}$ & $53 / 60$ (88\%) & $38 / 60(63 \%)$ & $6 / 60(10 \%)$ & $N=60$ \\
\hline Means per RA & 2.58 & 1.20 & 0.13 & $N=60$ \\
\hline
\end{tabular}

Table 5. Argumentation patterns of Move 2

As each discussion section comprises several occurrences of Move 2, the distributions of each argumentation pattern in each article is also explored. Pattern A occurs in nearly 90 percent of the articles, indicating that management academics show a propensity to position their research within the disciplinary network early in this section. Yet, writers appear to make extensive use of Pattern $\mathrm{B}$, which occurs in 63 percent of the articles, as well. Though scant in occurrence, Pattern $\mathrm{C}$ warrants further discussion as it contrasts starkly in form with the canonical disciplinary pattern. 
The following text segments (Figures 1 through 4 ) give some representative examples related to these argumentation patterns. These patterns facilitate more precise insights into the writer's rhetorical choices for claiming distinguished status for their research.

\subsubsection{Argumentation Pattern A}

In this prototypical argumentation pattern, writers generally launch with a bold proclamation of the theoretical implications of the study (Step 1A), attempting to activate readers' positive attitude toward the research. This strong positioning statement, as encoded in Step 1A, renders rigorous ensuing argumentation necessary to win reader endorsement. It is often immediately followed by either a comment on the state of the disciplinary field (see Figures 1 and 2) or by highlighting novel findings. Figure 1 illustrates how the writer negotiates the value of the specified contribution, primarily through recognizing a conflict with the literature (Step 2A).

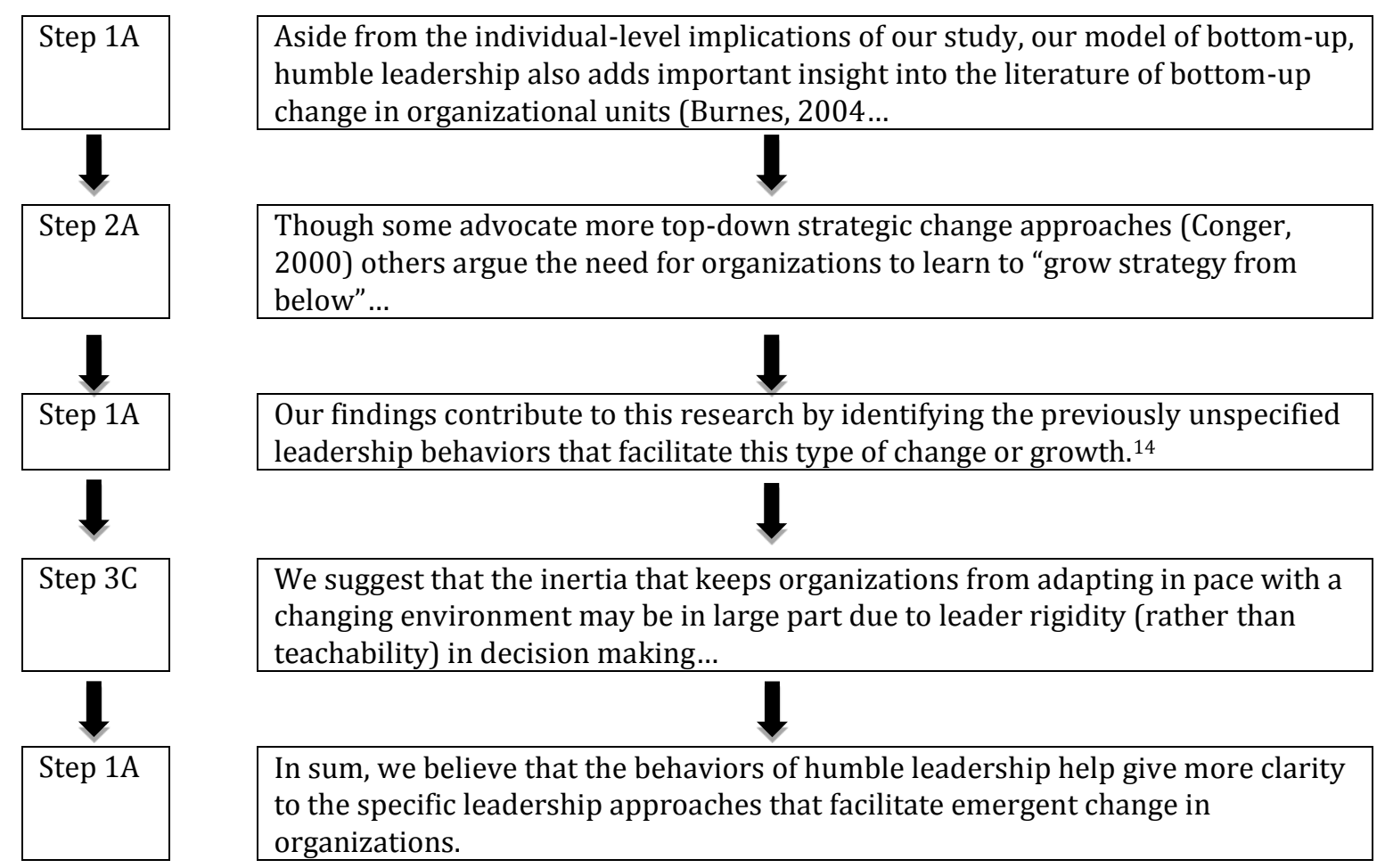

Figure 1. An example of Pattern A (AMJ, 7)

This rhetorical choice carves out the knowledge space to be occupied by the new findings. The reporting of established knowledge (Step 2A) and the new finding (Step 3C) is sandwiched with another overt marking of contribution (Step 1A in the middle). It not only illuminates how the results buttress one of the rival theoretical perspectives by delving into previously unexamined variables but also 
adds promotional flavor throughout the argumentation process. A careful elaboration of the meaning of the new findings (Step 3C) is then entailed to justify the theoretical contribution. This detailed explication delineates how the model of 'humble leadership' forms a new and important addition to the larger theoretical arena, revealing the contribution to be of a magnitude sufficient to substantially clarify the core logic of the aligned perspective. Prior literature is also deployed to build intellectual alliances for reinforcing the validity of the researcher's explanation, as shown in Step 3C. Quite tellingly, the writer strengthens the study's hook by concluding this move through the use of Step 1A at the end, thus boosting its theoretical implications. These rhetorical choices dexterously manipulate readers to regard the writer's value assertion in a favorable light.

\begin{tabular}{|c|c|}
\hline Step 1A & $\begin{array}{l}\text { These findings contribute to the literatures on organizational impression } \\
\text { management and social influence. }\end{array}$ \\
\hline Step 2B & $\begin{array}{l}\text { While a growing body of research has yielded important insights into how } \\
\text { corporate leaders manage the impressions of a firm's constituents in the wake of } \\
\text { image-threatening events... }\end{array}$ \\
\hline Step 1A & $\begin{array}{l}\text { In the present study, we contribute to the literature on organizational impression } \\
\text { management and the larger organizational literature on social influence }\end{array}$ \\
\hline Step 3B & $\begin{array}{l}\text { by identifying and examining a form of impression management that is likely to } \\
\text { be perceived as less self-serving than impression management by CEOs ... }\end{array}$ \\
\hline Step 2A & $\begin{array}{l}\text { Although studies on organizational impression management have typically } \\
\text { examined efforts by leaders... }\end{array}$ \\
\hline Step 2B & $\begin{array}{l}\text { Although these studies have made important contributions to our understanding } \\
\text { of impression management, they still examined forms of impression management } \\
\text { that constituents are likely to perceive as relatively self-serving... }\end{array}$ \\
\hline Step 3A & $\begin{array}{l}\text { In this study, we examined impression management by corporate leaders about } \\
\text { the leadership of particular other firms, rather than the industry at large... }\end{array}$ \\
\hline Step 3B & $\begin{array}{l}\text { Though leaders could benefit indirectly in some cases from engaging in such } \\
\text { behavior, our theory suggests why journalists are likely to perceive IM support as } \\
\text { relatively less self-serving than impression management... }\end{array}$ \\
\hline
\end{tabular}

Figure 2. An example of Pattern A (ASQ, 14) 
While the above rhetorical strategy does not involve a direct confrontation with established knowledge, Figure 2 indicates a different take on the argumentation pattern that also commences with Step 1A. To negotiate the value of theoretical advancement stated in Step 1A, a substantial amount of text is devoted to showcasing the theoretical background by evaluating the state of knowledge (Step 2B).

This instance not only embeds the findings more fully in the disciplinary landscape, but also represents a cogent redirection of existing theoretical perspectives. This example elucidates a more combative argumentation tactic, which functions to defend and justify the theoretical implication. It involves headon challenges to the prior literature, as illustrated in the recurrent enactment of Step 2B, carving out research space to be strategically occupied by the writer's novel study. This aggressive textual process with interpersonally charged attacks on other studies is primarily hedged with acknowledgement of contributions from prior literature, such as, "has yielded important insights" and "have made important contributions." It is further mitigated with a modest proposal of the theoretical generalizations of the current research (Step 3B at the end), through the deployment of the modal adjective 'likely' and verb 'could,' or the tentative reporting verb 'suggest'. This is conducive to toning down the theoretical confrontation between the new and accumulated knowledge by encoding the new knowledge with a tentative epistemological status and thus acknowledging each contribution as only a small portion of the knowledge-formation process (Bazerman, 1988).

\subsubsection{Argumentation Pattern B}

This argumentation pattern begins either by highlighting established knowledge (Step 2) or by featuring novel findings of the research (Step 3), to strategically set the scene for the theoretical value to surface. The former subtype starts by revealing the context of accepted knowledge first to identify spaces for original contribution, whereas in the latter subtype, the new findings rise to prominence at the outset, unfolding the new understanding as the epistemic grounds upon which claims of theoretical implications are advanced. This subtype can be clearly seen in Figure 3 below, in which the new findings serve as anchors for subsequent value negotiation. 

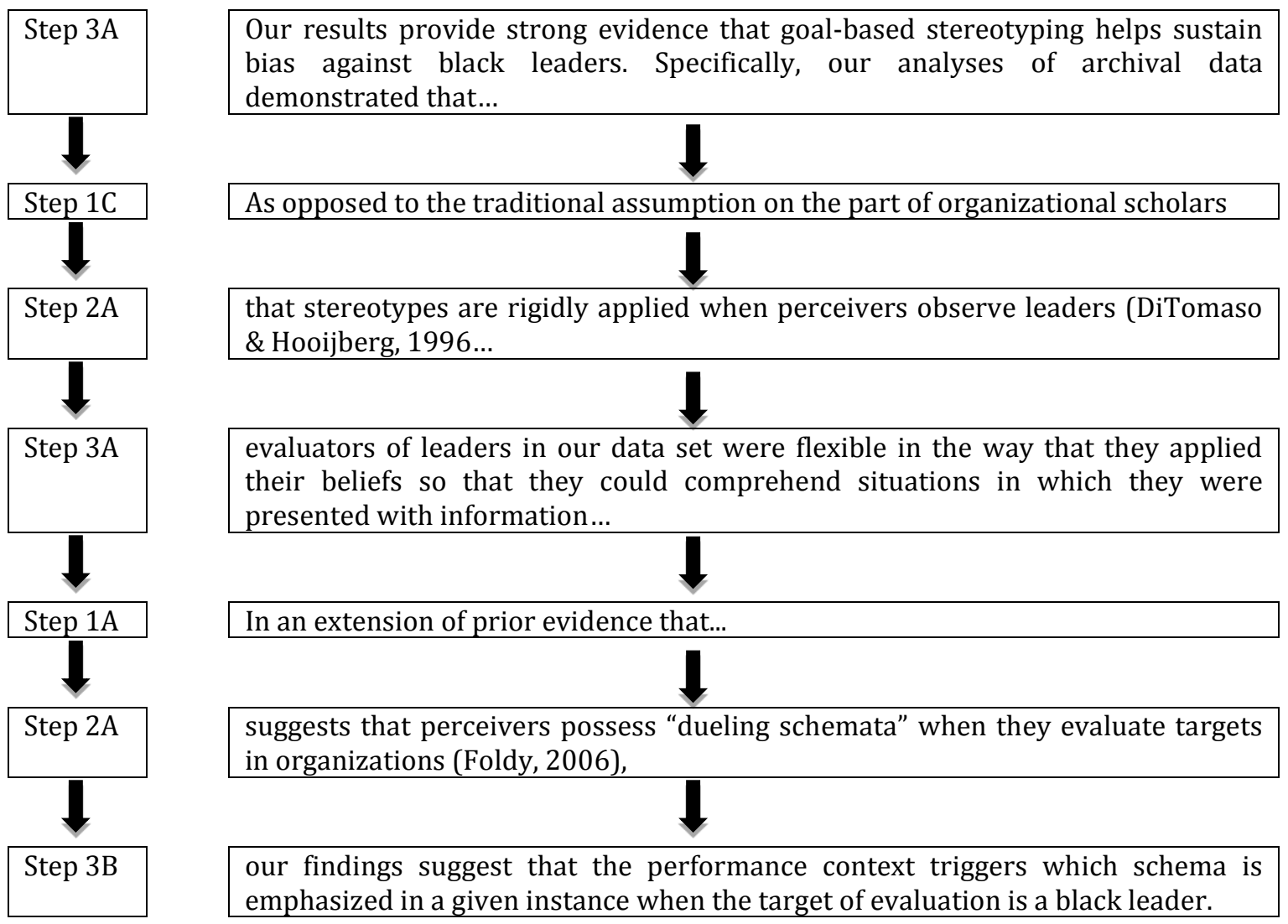

Figure 3. An example of Pattern B (AMJ, 4)

Unlike Pattern A, in which writers offer a catchy implication by emphasizing the value of their own findings at the start, the researcher whose work is shown above (Figure 3) gives strength to the new findings through a categorical assertion (Step 3A), realized linguistically as 'provide strong evidence,' and the factive reporting verb 'demonstrate.' The writer then moves on to invoke the significance of these findings by drawing readers' attention to their theoretical implications within the disciplinary network, first by Step $1 \mathrm{C}$ and then by Step 1A. These two discursive rhetorical strategies contextualize the finding in a fashion that envisages their theoretical advancement for the target knowledge domain. Following a direct confrontation with the entrenched literature (Step 1C), the validity of the new study is justified through meticulous description of the observed data (Step 3A in the middle) and further reinforced by its potential to extend the current knowledge (Step 1A in the middle). Through progressive articulation of how and why the novel finding challenges and extends the literature, new disciplinary knowledge is proposed at the end of this argumentation episode. In short, this subtype of Pattern B reveals an inductive reasoning strategy that is deployed to legitimize a forthcoming contribution to knowledge. To strengthen its argumentative foundation, the new finding is foregrounded at the outset, not only 
to establish a firm intellectual basis for determining theoretical implications, but also to warrant the prospective claim of theoretical value by providing empiricallybased evidence.

\subsubsection{Argumentation Pattern C}

Distinct from all the examples presented above, this argumentation pattern refrains from explicit articulation of any theoretical implication and commences with either Step 2 or 3. In the absence of Step 1 (see Figure 4 below), this pattern utilizes a rather intricate and sophisticated maneuver to connote and negotiate the theoretical value. In total, there are only eight instances of this pattern, evinced in six articles of ASQ and JMS. It should be noted that although no Step 1 occurs in this pattern, the authors of these studies have either provided a paragraph-length summary of contributions, or a brief global contribution statement in the introduction (Move 1) or conclusion (Move 6) of the discussion section. This argumentation pattern is utilized to defend the value signposted in Moves 1 or 6 . Such structuring arrangements merit attention as Pattern $\mathrm{C}$ fleshes out distinct variations in negotiating theoretical implications.

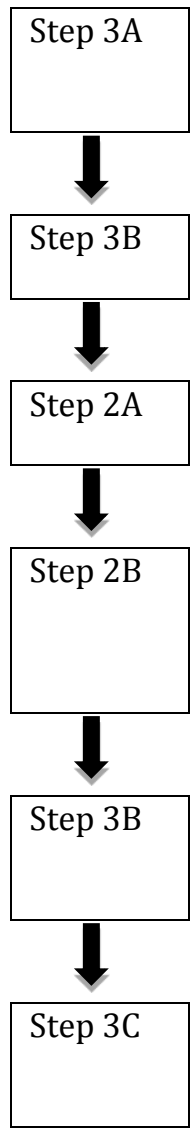

While the novice entrepreneur in this study appeared to be aware that visual symbols could impact his status in terms of legitimacy, he did not consistently direct attention to how he was being perceived visually.

The findings also suggest that the serial entrepreneurs were more successful at employing a wider range of visual symbols.

While prior experience of a field or industry has been extensively examined as the basis for identifying and designing new ventures (e.g. Baron, $2000 \ldots$

less research has explored how prior experience can impact on the development of legitimacy and resource acquisition (Dalziel et al., 2011). The limited research which does examine the link between prior experience and resource acquisition tends to focus on ...

What is clear from the findings of this study is that the more experienced entrepreneurs did not rely solely on previous contacts or social ties to obtain resources (Dimov, 2010)...

This is perhaps because they build up more extensive understanding of the various frames of meaning that can be conveyed through visual symbols ... (Goffman, 1974)...

Figure 4. An example of Pattern C (JMS, 3) 
To validate the claim of theoretical advancement made near the end of this move, this instance begins by reporting the current accomplishments (Steps 3A and 3B) and proceeds to contextualize the new findings by reviewing the disciplinary knowledge landscape (Step 2A). Instead of overtly marking the research value by means of Step 1, the theoretical implication is suggested at points of controversy by locating the findings (Step 3B) within the broader theoretical literature through an overt indication of a gap (Step 2B). By articulating the current finding in relation to the identified research gap, as witnessed in Step 3B at the end of this Move, "What is clear from the findings of this study is that ...", the theoretical contribution is insinuated through reference to the notable modifications that the new findings make to the established knowledge. The new discovery confronts the scientific claim in the accepted literature which is reported in Step 2B and receives support from other literature. To defend the potential contribution of the new study, the challenged literature is delineated as relatively limited in scope and based upon a small number of studies, suggesting its validity may be questionable, even though no direct criticism of any methodological or epistemological flaws is leveled. The academic conflict between the new finding and the established knowledge is resolved strategically through brushing aside established literature and adding support to the new research through citation. This has been found to be a common discursive practice to tactically resolve an academic conflict in applied linguistics (Cheng \& Unsworth, 2016).

\section{DISCUSSION}

Drawing upon genre-based research, this study explores the enactment of a specific Move 'Establishing theoretical implication' in management RA discussion sections, and clarifies rhetorical paths for crafting a theoretical contribution. This study, thus, addresses the scant treatment of a long-standing theme in management scholarship, and has several theoretical and pedagogical implications for academic writing and evaluation.

\subsection{Contributions to ESP/EAP scholarship}

As noted, the construct of theoretical implication has been widely discussed, but its rhetorical construction has not yet been systematically investigated. By interpreting the act of theoretical implication in the broadest possible sense to include all theoretical positioning statements, instead of narrowly restricting this act to articulation of overt contribution (i.e. Step 1A), the theoretical value of a new study can have different levels of implication to illuminate the current state of a pertinent knowledge domain. Some theoretical implications which break ground from extant knowledge can radically change academic discourse as new research is 
published (i.e. Step 1A/1C/1D), whereas other implications may reinforce or crystalize the current state of knowledge (i.e. Step 1B/1D). Built upon this perspective, this study illuminates the rather elusive construct of theoretical implication by conceptualizing it as a rhetorical move. The focal move is instantiated in three essential steps, in which Steps 2 and 3 represent previous scholarship and novel research, respectively, in the continuum of disciplinary knowledge formation, while Step 1 bridges past and present research and signals the potential theoretical value of the new research.

To transform a new finding into valuable discipline knowledge requires contextualizing the new finding in a relevant theoretical domain, ascribing value to the finding, and interpreting and explaining its meaning in terms of its theoretical insights. The overall complexity of the argumentation patterns found in different constructions of this move offers critical theoretical insights into this professional academic practice. Surprisingly, the articulation of theoretical implication stops short of categoricality, as it can be formulated explicitly through Step 1 or, on rare occasions, tacitly suggested via the interface of Steps 2 and 3. In these occasions, theoretical value can be overtly described in Moves 1 or 6 but not articulated in Move 2. Moreover, although this move is typically achieved through a trajectory headed by Step 1, it can be initiated by virtually any (sub)step as noted in argumentation patterns $\mathrm{B}$ and $\mathrm{C}$. The preliminary sketch of this move gestures toward a rather elastic construction and sophisticated rhetorical exposition for advocating theoretical breakthroughs, as well as demonstrating a new study's capacity to broaden the theoretical scope of the knowledge construction continuum.

\subsection{Pedagogical implications}

Based on the present findings, several pedagogical implications can be drawn. Given the complex and subtle nature of RA discussions, we can theorize a pedagogical framework to introduce novice management academics to a range of typical rhetorical choices available in this textual territory. First, to address the disciplinary call for greater emphasis on constructing theoretical implications (Bergh, 2003; Corley \& Schinoff, 2017; Geletkanycz \& Tepper, 2012), the proposed scheme of this focal move can demonstrate to students ways in which to establish theoretical implications beyond articulating the token statement of contribution. Additionally, the lack of a fixed linear sequence for observed argumentation patterns also shows that students should be advised that these steps are possible resources to be exploited in a flexible manner, not mandatory rules to be rigidly adhered to in textual construction. This flexibility can enable students to use these writing options to their own rhetorical advantage.

Furthermore, to account for the inherently argumentative feature of this move, as stressed in Bergh (2003), pedagogical focus should also illuminate pathways for successfully achieving this discursive act. That is, meaningful integration of argumentation into writing instruction can reveal to students which 
elements provide the persuasive force underlying this move beyond the textstructuring mechanisms of rhetorical schemes. Careful attention to the negotiation process can provide useful scaffolds not only to deepen students' awareness of the persuasive and argumentative features embedded in this move but also to sharpen their argumentative skills in the disciplinary context.

Among a plethora of rhetorical variations in negotiating theoretical implications, novice scholars can be encouraged to start by practicing the most prominent argumentation pattern, which initiates a move by overtly announcing the theoretical implication and then offering rigorous justification of the claimed value. By rehearsing this argumentative tactic, students can avoid the common pitfall of "rehashing results" in RA discussion sections (Geletkanycz \& Tepper, 2012: 258), that is, restating findings without discussion of how and why they are theoretically significant to the target discipline.

\section{CONCLUSION}

This study has added a fresh perspective on the rhetorical construction of RA discussion sections in management scholarship by proposing a new move focused on theoretical implication, distinct from other evaluative acts. In its delineation of rhetorical components and negotiation processes, this research also contributes to a more profound understanding of academic promotion, and offers several pedagogical implications for novice scholars engaging in academic writing tasks. It should be cautioned that generalizations about rhetorical practices in the field of management science are to be avoided, as the corpus used in this study is extracted from RAs of the most eminent journals. The highly marked promotional tactics observed in the corpus might be attributable to the intense competitiveness of achieving visibility by publishing in these top-ranked academic publications. Thus, future researchers are encouraged to substantiate the current findings from intra-disciplinary perspectives by scrutinizing publications either in business subdisciplines or with different academic rankings within the field, in order to recast our understanding of the phenomenon of academic evaluation in the RAs of management science.

[Paper submitted 28 Apr 2020]

[Revised version received 10 Jun 2020]

[Revised version accepted for publication 17 Jun 2020]

\section{Acknowledgement}

This study was supported by a research project financed by the Taiwan Ministry of Science and Technology (grant NSC-102-2410-H-415-008-MY2). I am very grateful to the anonymous reviewers and the editor of ESP Today journal for their constructive comments. 


\section{References}

Bartunek, J. M., \& Rynes, S. (2010). The construction and contributions of "implications of practice": What's in them and what might they offer? Academy of Management Learning \& Education, 9,100-117. https://doi.org/10.5465/amle.9.1.zqr100

Basturkmen, H. (2009). Commenting on results in published research articles and masters dissertations in language teaching. Journal of English for Academic Purposes, 8(4), 241-251. https://doi.org/10.1016/j.jeap.2009.07.001

Basturkmen, H. (2012). A genre-based investigation of discussion sections of research articles in dentistry and disciplinary variation. Journal of English for Academic Purposes, 11(2), 134-144. https://doi.org/10.1016/j.jeap.2011.10.004

Bazerman, C. (1988). Shaping written knowledge: The genre and activity of the experimental article in science. Madison: The University of Wisconsin Press.

Bergh, D. D. (2003). From the editors: Thinking strategically about contribution. Academy of Management Journal, 46(2), 135-136. https://doi.org/10.5465/amj.2003.17481820

Berkenkotter, C., \& Huckin, T. N. (1995). Genre knowledge in disciplinary communication: Cognition/culture/power. Hillsdale, New Jersey: Lawrence Erlbaum Associates.

Bhatia, V. K. (2004). Worlds of written discourse. New York, NY: Continuum.

Cheng, F. W., \& Unsworth, L. (2016). Stance-taking as negotiating academic conflict in applied linguistics research article discussion sections. Journal of English for Academic Purposes, 24, 43-57. http://dx.doi.org/10.1016/j.jeap.2016.09.001

Colquitt, J., \& Zapata-Phelan, G. (2007). Trends in theory building and theory testing: A five-decade study of the Academy of Management Journal. Academy of Management Journal, 50(6), 1281-1303. https://doi.org/10.5465/amj.2007.28165855

Corley, K., \& Gioia, D. (2011). Building theory about theory building: What constitutes a theoretical contribution? Academy of Management Review, 36(1), 12-32. https://doi.org/10.5465/amr.2009.0486

Corley, K. G., \& Schinoff, B. S. (2017). Who, me? An inductive study of novice experts in the context of how editors come to understand theoretical contribution. Academy of Management Perspectives, 31(1), 4-27. https://doi.org/10.5465/amp.2015.0131

Cornelissen, J. P., \& Durand, R. (2014). Moving forward: Developing theoretical contributions in management studies. Journal of Management Studies, 51, 9951022. https://doi.org/10.1111/joms.12078

De Keyser, B., Guiette, A., \& Vandenbempt, K. (2019). On the use of paradox for generating theoretical contributions in management and organization research. International Journal of Management Reviews, 21, 143-161. https://doi.org/10.1111/ijmr.12201

Del Saz-Rubio, M. M. (2011). A pragmatic approach to the macro-structure and metadiscoursal features of research article introductions in the field of agricultural science. English for Specific Purposes, 30(4), 258-271. https://doi.org/10.1016/j.esp.2011.03.002

Geletkanycz, M., \& Tepper, B. J. (2012). From the editors: Publishing in AMJ-part 6: Discussing the implications. Academy of Management Journal, 55(2), 256-260. https://doi.org/10.5465/amj.2012.4002

Geng, Y., \& Wharton, S. (2016). Evaluative language in discussion sections of doctoral theses: Similarities and differences between L1 Chinese and L1 English writers. Journal of English for Academic Purposes, 22, 80-91. https://doi.org/10.1016/j.jeap.2016.01.001 
Hyland, K. (2015). Academic publishing: Issues and challenges in the construction of knowledge. Oxford: Oxford University Press.

ISI Web of Science. (2013). Journal citation reports: Social science edition. New York: Thomson Reuters.

Kanoksilapatham, B. (2015). Distinguishing textual features characterizing structural variation in research articles across three engineering sub-discipline corpora. English for Specific Purposes, 37, 74-86. http://dx.doi.org/10.1016/j.esp.2014.06.008

Kelly, G. J., \& Takao, A. (2002). Epistemic levels in argument: An analysis of university oceanography students' use an evidence in writing. Science Education, 86, 314-342. https://doi.org/10.1002/sce.10024

Knorr-Cetina, K. (1995). Laboratory studies: The cultural approach to the study of science. In S. Jasanoff., G. E. Markle., J. C. Peterson, \& T. Pinch (Eds.), Handbook of science and technology studies (pp. 140-66). Thousand Oaks: Sage publications.

Landis, J. R., \& Koch, G. G. (1977). The measurement of observer agreement for categorical data. Biometrics, 33(1), 159-174. http://doi.org/10.2307/2529310

Lewin, B. A., Fine, J., \& Young, L. (2001). Expository discourse: A genre-based approach to social science research texts. London: Continuum.

Lim, J. M. H. (2006). Method sections of management research articles: A pedagogically motivated qualitative study. English for Specific Purposes, 25(3), 282-309. https://doi.org/10.1016/j.esp.2005.07.001

Lim, J. M. H. (2012). How do writers establish research niches? A genre-based investigation into management researchers' rhetorical steps and linguistic mechanisms. Journal of English for Academic Purposes, 11(3), 229-245. https://doi.org/10.1016/j.jeap.2012.05.002

Lindeberg, A-C. (2004). Promotion and politeness: Conflicting scholarly rhetoric in three disciplines. Turku, Finland: Åbo Akademi University Press.

Liu, M. S. M., \& Lim, J. M. H. (2014). How do writers evaluate their own empirical research? A genre-based inquiry into economics journal papers. Procedia - Social and Behavioral Science, 134,13-22. https://doi.org/10.1016/j.sbspro.2014.04.219

Liu, Y., \& Buckingham, L. (2018). The schematic structure of discussion sections in applied linguistics and the distribution of metadiscourse markers. Journal of English for Academic Purposes, 34, 97-109. https://doi.org/10.1016/j.jeap.2018.04.002

Locke, K., \& Golden-Biddle, K. (1997). Constructing opportunities for contribution: Structuring intertextual coherence and 'problematizing' in organizational studies. Academy of Management Journal, 40, 1023-1062. https://doi.org/10.5465/256926

Martín, P., \& León Pérez, I. K. (2014). Convincing peers of the value of one's research: A genre analysis of rhetorical promotion in academic texts. English for Specific Purposes, 34, 1-13. https://doi.org/10.1016/j.esp.2013.09.002

Nwogu, K. N. (1997). The medical research paper: Structure and functions. English for Specific Purposes, 16(2), 119-138. https://doi.org/10.1016/S0889-4906(97)85388-4

O'Donnell, M. (2012). UAM CorpusTool: Text annotation for the 21st century. Retrieved from http://corpustool.com/

Peacock, M. (2002). Communicative moves in the discussion section of research articles. System, 30(4), 479-497. https://doi.org/10.1016/S0346-251X(02)00050-7

Shaw, J. D., Bansal, P., \& Gruber, M. (2017). From the editors: New ways of seeing: Elaboration on a theme. Academy of Management Journal, 60(2), 397-401. https://doi.org/10.5465/amj.2017.4002 
Swales, J. M. (1990). Genre analysis: English in academic and research settings. Cambridge: Cambridge University Press.

Swales, J. (2004). Research genres: Exploration and applications. Cambridge: Cambridge University Press.

Tessuto, G. (2015). Generic structure and rhetorical moves in English-language empirical law research articles: Sites of interdisciplinary and interdiscursive cross-over. English for Specific Purposes, 37, 13-26. https://doi.org/10.1016/j.esp.2014.06.002

Tseng, M-Y. (2018). Creating a theoretical framework: On the move structure of theoretical framework sections in research articles related to language and linguistics. Journal of English for Academic Purposes, 33, 82-99. https://doi.org/10.1016/j.jeap.2018.01.002

Whetten, D. A. (1989). What constitutes a theoretical contribution? Academy of Management Review, 14, 490-495. https://doi.org/10.5465/amr.1989.4308371

Yang, R., \& Allison, D. (2003). Research articles in applied linguistics: Moving from results to conclusions. English for Specific Purposes, 22(4), 365-385. https://doi.org/10.1016/S08894906(02)00026-1

FEI-WEN CHENG is Professor in the Department of Foreign Languages at National Chiayi University, Taiwan where she teaches a variety of courses of advanced academic literacy and English for specific purposes. Her main areas of research include academic discourse, genre analysis, and multimodality.

\section{Appendix}

Text examples of each substep

\begin{tabular}{|c|c|}
\hline Step & Text examples \\
\hline \multicolumn{2}{|l|}{ Step 1: Stating theoretical implication } \\
\hline $\begin{array}{l}\text { Step 1A: Highlighting contribution to the } \\
\text { field }\end{array}$ & First, the results contribute to research on power... $(A S Q, 5)$ \\
\hline $\begin{array}{l}\text { Step 1B: Expressing consistency with past } \\
\text { research }\end{array}$ & $\begin{array}{l}\text { Our results are consistent with those of Mayer et al. (2009) } \\
\text { and Walumbwa and Schaubroeck (2009)... (AMJ, 15) }\end{array}$ \\
\hline $\begin{array}{l}\text { Step 1C: Expressing inconsistency with past } \\
\text { research }\end{array}$ & $\begin{array}{l}\text { Contrary to the information exchange perspective... (JOM, } \\
\text { 10) }\end{array}$ \\
\hline $\begin{array}{l}\text { Step 1D: Expressing consistency/ } \\
\text { inconsistency with hypothesis/proposition }\end{array}$ & $\begin{array}{l}\text { The two hypotheses that were not supported were } \mathrm{H} 4 \mathrm{~b} \text { and } \\
\text { H5b, which suggested ... (ASQ, } 3 \text { ) } \\
\text { In contrast to our results for black leaders, the current } \\
\text { results support the theoretical proposition that ... (AMJ, 4) }\end{array}$ \\
\hline \multicolumn{2}{|c|}{ Step 2: Showcasing the theoretical background } \\
\hline Step 2A: Reviewing the state of the field & $\begin{array}{l}\text { Cross-cultural researchers (cf. Adler, 1997; Guillen, 1994) } \\
\text { note that ... Brockner et al. (2001) suggested that ...(JMS, 15) }\end{array}$ \\
\hline Step 2B: Evaluating prior research & $\begin{array}{l}\text { Second, prior middle management and championing } \\
\text { literatures often have focused on ... but failed to distinguish } \\
\text { among such activities... (JOM, 12) }\end{array}$ \\
\hline
\end{tabular}




\begin{tabular}{|l|l|}
\hline \multicolumn{2}{|l|}{ Step 3: Justifying the theoretical value } \\
\hline $\begin{array}{l}\text { Step 3A: Presenting results/research } \\
\text { purpose }\end{array}$ & $\begin{array}{l}\text { As one illustration, data show that ... (AMJ, 6) } \\
\text { Here we explore conversations to engage seniors, peers, and } \\
\text { subordinates in change. (JMS, 2) }\end{array}$ \\
\hline Step 3B: Interpreting results & $\begin{array}{l}\text { Our results highlight the key role of founding team } \\
\text { endowments in opportunity identification ... (JOM, 14) }\end{array}$ \\
\hline Step 3C: Explaining results & $\begin{array}{l}\text { One possible explanation is that high levels of business model } \\
\text { innovation redirect attention and firm activity ... (JMS, 6) }\end{array}$ \\
\hline Step 3D: Evaluating the results & $\begin{array}{l}\text { Given the results presented above, it is not surprising that } \\
\text { the resulting classification structure ... (ASQ, 7) }\end{array}$ \\
\hline
\end{tabular}

